\title{
EDUCAÇÃO EM DIREITOS HUMANOS E RELAÇÕES SOCIAIS DE GÊNERO: DISCUSSÕES EM BUSCA DE UMA "EDUCAÇÃO MAIS HUMANA"
}

\author{
Talita Santana Maciel ${ }^{1}$ \\ Tânia Suely Antonelli Marcelino Brabo ${ }^{2}$
}

\section{Resumo}

Este texto tem por objetivo refletir, por meio de estudo bibliográfico, sobre os pressupostos da educação em direitos humanos, especialmente no que concerne às relações sociais de gênero, e apresentar aspectos teórico-metodológicos que possam subsidiar a prática pedagógica em sala de aula. Entendemos que, em meio ao contexto neoliberal e das consequências negativas que tal ideologia causou, a educação em direitos humanos torna-se um dos instrumentos fundamentais para a concretização de uma cultura dos direitos humanos que seja capaz de transformar relações e práticas sociais, inclusive relações sociais de gênero, concorrendo para a perpetuação de uma "educação mais humana". Para tanto, é essencial que o fazer educativo tenha caráter político, caminhe em uma perspectiva de formação axiológica e aconteça cotidianamente.

Palavras-chave: Educação; Direitos Humanos; Gênero; Neoliberalismo; Professor(A)

\footnotetext{
1 Mestranda do Programa de Pós-Graduação em Educação pela Universidade Estadual Paulista "Júlio de Mesquita Filho"- UNESP-FFC-Campus de Marília. Endereço: Rua Armando Davoli, 553-Vera Cruz-SP-Brasil, CEP-17560-000. Endereço eletrônico: talita.s.maciel@ hotmail.com

${ }^{2}$ Mestre em Educação pela FFC-UNESP-Campus de Marília. Doutorado em Sociologia pela FFLCH-USP. Pósdoutorado em Educação pela Universidade do Minho, Braga-Portugal. Pós-Doutorado em Educação pela Universidade de Valência-Espanha. Endereço: Rua Cel. José Braz, 1105-Marília-SP- Brasil, CEP-17502-010. Endereço eletrônico: tamb@ marilia.unesp.br
} 


\section{INTRODUÇÃO}

O conceito de direitos humanos ancorado na história expressa os acontecimentos passados e também os vivenciados hoje. Sua construção foi marcada pelas lutas emancipatórias do povo e acompanha os episódios da realidade atual. "A construção dos direitos humanos se faz todo dia, se faz nas lutas concretas, se faz nos processos históricos que afirmam e inovam direitos a todo tempo.” (CARBONARI, 2009, p. 146).

Do mesmo modo, a educação em direitos humanos e suas políticas surgiram em decorrência de acontecimentos históricos, se aprimorando em defesa de uma cultura mais igualitária, justa e harmônica. A educação em direitos humanos caminha com os acontecimentos vivenciados por toda a humanidade, a qual precisou - e ainda precisa - ter asseguradas as suas condições mínimas de proteção e sobrevivência, tais como o direito ao respeito, à igualdade, à segurança, à propriedade, à educação, à não-violência e ao próprio direito à vida.

Nesse sentido, este texto tem por objetivo refletir, por meio de estudo bibliográfico, sobre os pressupostos da educação em direitos humanos, especialmente no que concerne às relações sociais de gênero, e apresentar aspectos teórico-metodológicos que possam subsidiar a prática pedagógica em sala de aula.

Historicamente, a identidade feminina foi construída com base na subordinação e dependência, características culturais e ideológicas que influenciaram no papel da mulher em sociedade e na divisão sexual do trabalho. À mulher foi concedida uma meia cidadania imperfeita por meio do processo de socialização formal e informal. Principalmente nos anos de 1980, o movimento feminista contribuiu para a evolução do direito da mulher brasileira, momento em que houve intenso debate sobre o papel da mulher na sociedade e uma campanha política favorável à cidadania da mulher. Na década de 1990, acorreu a implementação de políticas públicas voltadas à igualdade de oportunidades, à garantia de direitos, porém, marcadas pelo ideário neoliberal (BRABO, 2009).

Entendemos que, em meio ao contexto neoliberal e das consequências negativas que tal ideologia causou, a educação em direitos humanos torna-se um dos instrumentos fundamentais para a concretização de uma cultura dos direitos humanos que seja capaz de transformar relações e práticas sociais, inclusive relações sociais de gênero. Para tanto, é essencial que a educação em direitos humanos tenha caráter político, caminhe em uma 
perspectiva de formação axiológica e aconteça cotidianamente. Além disso, os(as) professores(as) assumem importante papel na educação em direitos humanos, uma vez que dispõem da possibilidade de influência para a realização de transformações grandiosas em prol da humanidade.

\section{CONTEXTO NEOLIBERAL E AS POLÍTICAS DA EDUCAÇÃO EM DIREITOS HUMANOS}

Historicamente o Brasil foi caracterizado por desigualdades que, devido à ordem mundial reinante, fundamentada na concepção neoliberal, vêm crescendo incessantemente, aumentando o número de excluídos(as) e destituindo muitas pessoas das condições de dignidade humana.

Nesse contexto neoliberal, conforme Benevides (1998), os direitos políticos sobrepõem-se aos direitos sociais, ocasionando constantes violações dos direitos mais elementares dos seres humanos. Sacavino (2000) também alerta para a condenação de milhões de homens, mulheres e crianças à marginalização ocasionada pelo modelo econômico vigente, assim como outros(as) autores(as), dentre eles(as) Horta (2000), Candau (2000) e Cardoso (2009).

Nesse momento do texto, destaca-se, portanto, a importância de traçar o contexto geral da ideologia que provocou danos à sociedade, aprofundando questões históricas, econômicas e políticas que impactaram a vida social. Dessa forma, cabe apresentar primeiramente quais são os princípios do liberalismo, pois, assim como afirma Pereira (2004, p. 22):

\footnotetext{
O tratamento teórico dado ao Estado pelos neoliberais se assemelha ao dos liberais clássicos. Mas, a mesma teoria em momentos históricos diferentes, atua diferentemente na sociedade. Os liberais contribuíram para a evolução sócio-política e econômica da sociedade. Ao se contraporem ao absolutismo e ao feudalismo os liberais assumiram um papel revolucionário, diferentemente dos neoliberais que utilizando as mesmas teses liberais na contemporaneidade assumem um papel reacionário.
}

No período que antecedeu a Revolução Industrial, algumas legislações repressivas foram estabelecidas com o intuito de obrigar as pessoas pobres a aceitarem qualquer trabalho que lhes fosse oferecido - já que necessitavam do trabalho para sobreviver -, regular a remuneração do trabalho, de forma que os trabalhadores não poderiam negociar formas de 
remuneração e assim manter a organização tradicional do trabalho (CASTEL, 1998 apud BEHRING; BOSCHETTI, 2011).

Tais legislações pré-capitalistas mudaram com a Revolução Industrial e, se antes os pobres estavam sob as condições de leis sociais punitivas e restritivas, com o avanço do livre mercado eles foram lançados num contexto de servidão da liberdade.

O capitalismo começou a ganhar força após a Revolução Industrial quando um conjunto de mudanças em relação à liberdade e competividade na compra e venda da força de trabalho começou a ocorrer. Na sociedade capitalista o trabalho passou a ter sentido de atividade natural de produção para a troca, perdendo o significado pré-industrial de processo de humanização atrelado à vida social. Passaram a ser constituídas relações para acumulação, através da expropriação da mais-valia e do "trabalho livre".

O período de meados do século XIX até a década de 1930 foi marcado pelo predomínio do liberalismo e das ideias de trabalho como mercadoria e de livre mercado que as sustentam. A justificativa econômica do liberalismo, alimentada pelas teses de David Ricardo e Adam Smith, está pautada no interesse individual, ou seja, cada indivíduo deve agir segundo seu próprio interesse econômico e também voltar-se para a coletividade de indivíduos para que seja atingido o bem-estar.

Para o liberalismo, o funcionamento livre do mercado produz o bem comum, conquanto não haja intervenção estatal. Adam Smith defendia que existe a necessidade de um corpo de leis que garanta maior liberdade ao mercado, mas que não tenha caráter intervencionista.

O liberalismo em seu surgimento instaurou uma nova forma de pensar a economia e a sociedade, uma vez que os "fundadores" dessa ideologia pretendiam romper com a hegemonia de poder que detinha o Estado absoluto, a aristocracia e o clero e consolidar a burguesia como classe politicamente dominante. Em resumo, nas palavras de Behring e Boschetti (2011, p. 59-60, grifo do autor),

[...] a procura do interesse próprio pelos indivíduos, portanto, seu desejo natural de melhorar as condições de existência, tende a maximizar o bem-estar coletivo. Uma mão invisível - o mercado - leva os indivíduos a promover um fím que não fazia parte de sua intenção inicial. Nesse sentido, o bem-estar pode ser um efeito nãointencional da avareza. A "loucura das leis humanas" não pode interferir nas leis naturais da economia, e por isso o Estado deve apenas fornecer a base legal, para que o mercado livre possa maximizar os "benefícios aos homens". Trata-se, portanto, de um Estado mínimo, sob forte controle dos indivíduos que compõem a sociedade civil, na qual se localiza a virtude. [...] A coesão social se originaria na sociedade civil, com a mão invisível do mercado e o cimento ético dos sentimentos 
morais individuais, fundados na perfectibilidade humana. Para Smith, não há, portanto, contradição entre acumulação de riqueza e coesão social.

O predomínio do individualismo, da liberdade e competitividade, a ideia de que o bem-estar individual maximiza o bem-estar coletivo e a naturalização da miséria, são elementos do liberalismo que possibilitam compreender a reduzida intervenção estatal na forma de consolidação de políticas sociais.

Na segunda metade do século XIX e início do século XX as bases materiais e subjetivas do liberalismo começaram a se enfraquecer devido, principalmente, a dois processos político-econômicos: o crescimento do movimento operário e a concentração e monopolização do capital.

Após a crise de 1929 - 1932 a monopolização do capital caracteriza a economia. Ocorreram intensas mudanças no mundo da produção, combinadas à "revolução" Keynesiana, ao fordismo, ao contexto pós-guerra mundial e da Guerra Fria. Tais mudanças denominaram o período de 1930 - 1970 (aproximadamente) como "anos de ouro" e ao mesmo tempo formaram a base material para a expansão dos direitos sociais durante a experiência do Walfare State.

John Maynard Keynes, como meio de saída da profunda crise, defendeu a liberdade individual e a economia de mercado dentro de uma lógica diferente do liberalismo burguês. Keynes defendia um Estado mais intervencionista,

[...] a planificação indicativa da economia; a intervenção na relação capital/ trabalho através da política salarial e do "controle de preços"; a distribuição de subsídios; a política fiscal; a oferta de créditos combinada a uma política de juros; e as políticas sociais. (BEHRING; BOSCHETTI, 2011, p. 86).

Após a Segunda Guerra Mundial um consenso se instaurou entre as classes sociais, ocasionando o estabelecimento de acordos e compromissos que permitiram a expansão do chamado Walfare State: momento em que o Estado assumiu a responsabilidade de oferecimento de empregos, prestação pública de serviços sociais, assistência social e regulação da economia.

Tal fase expansiva do capitalismo começou a se esgotar na década de 1960, cedendo espaço ao pensamento neoliberal, rompendo com o pleno emprego keynesiano-fordista e com o avanço das políticas sociais. 
Anderson (1995 apud PEREIRA, 2004), afirma que o neoliberalismo surgiu como oposição crítica e reação política e teórica ao pensamento de Estado intervencionista e de bem-estar que se consolidava nas práticas políticas dos governos norte-americano e europeu. Friedrich Hayek, precursor da nova ideologia, em seu livro "O Caminho da Servidão" de 1994, criticou qualquer forma de intervenção do governo na economia e em 1947 reuniu diversos pensadores que se alinhavam com seus ideais neoliberais.

O processo de ascensão do pensamento neoliberal evidencia-se como solução para a crise do sistema capitalista da década de 1970 quando se tornou visível o fim do fordismo. Para os neoliberais, a gênese da crise encontrava-se no poder excessivo dos sindicatos e no movimento operário que, ao conseguir a ampliação dos direitos sociais, prejudicaram a lucratividade das empresas e a acumulação de capital (PEREIRA, 2004).

A solução para a crise proposta pelos neoliberais foi a permanência de um Estado mínimo e um governo forte, todavia o sentido de forte relaciona-se apenas ao controle do poder dos sindicatos e controle dos gastos com direitos sociais, sem que haja intervenção do Estado na economia. Paulatinamente, os ideais neoliberais foram sendo incorporados e aceitos pela sociedade, pois as propostas dos defensores do intervencionismo tornaram-se cada vez mais inconsistentes para solucionar os problemas causados pela crise no sistema capitalista.

Assim emergiu a doutrina que, com propostas drásticas, afetou a vida social, instaurou políticas perversas ao âmbito educacional, contribuiu para com a depredação do trabalho e destitui muitas pessoas de condições de uma vida digna. O neoliberalismo:

Representa uma regressão do campo social e político e corresponde a um mundo em que o senso social e a solidariedade atravessam uma grande crise [...]. No discurso neoliberal a educação deixa de ser parte do campo social e político para ingressar no mercado e funcionar a sua semelhança. (MARRACH, 2015, p. 1, grifo do autor).

Essa realidade, marcada pela violação dos direitos humanos, demanda uma nova ordem social pautada em uma perspectiva axiológica que preze a igualdade, a liberdade e solidariedade, bem como todos os princípios da Declaração Universal dos Direitos Humanos, onde se encontra a base de uma sociedade democrática.

Em meio ao contexto de avanço do projeto neoliberal e das consequências negativas que ele proporcionou - como o desemprego, o aumento das formas de violência, a exclusão, a anomia social -, torna-se urgente o desenvolvimento de uma cultura dos direitos humanos que seja capaz de transformar práticas de convivência, práticas sociais e políticas, e também que 
EDUCAÇÃO EM DIREITOS HUMANOS E RELAÇÕES SOCIAIS DE GÊNERO: DISCUSSÕES EM BUSCA DE UMA "EDUCAÇÃO MAIS HUMANA"

dê voz e força aos grupos excluídos, para que esses sejam sujeitos de sua própria história (CANDAU; SACAVINO, 2000).

A discussão sobre a necessidade de uma educação em direitos humanos não foi só vislumbrada no plano das ideias. O Programa Nacional de Direitos Humanos II (PNDH) possui propostas para a educação, dentre elas "fortalecer programas de educação em direitos humanos nas escolas de ensino fundamental e médio, com base na utilização dos 'temas transversais’ estabelecidos pelos Parâmetros Curriculares Nacionais - PCNs” (BRASIL, 2002).

Foi elaborado em 2003 e publicado em 2006 o Plano Nacional de Educação em Direitos Humanos (PNEDH), que representou o movimento internacional e nacional em defesa dos direitos humanos, da ampliação dos mesmos e do fortalecimento da democracia (SILVA, 2010). Após revisão e atualização, uma nova versão do PNEDH foi publicada em 2013 e no ano de 2012 foram publicadas as Diretrizes Curriculares Nacionais para a Educação em Direitos Humanos.

\section{EDUCAR EM DIREITOS HUMANOS: SUBSÍDIOS PARA A PRÁTICA PEDAGÓGICA}

Embora as declarações e os documentos elaborados ao longo da história e que contemplam os direitos humanos representem ganhos significativos à sociedade, a concretização dos direitos humanos na prática não é um processo simples nem natural. Por isso, educar em direitos humanos implica em proporcionar "significados práticos a uma vivência baseada na pluralidade de modos de vida e no respeito à diversidade" (DIAS; PORTO, 2010, p. 32), ou seja, a educação em direitos humanos permite que as premissas da Declaração Universal dos Direitos Humanos sejam vivenciadas cotidianamente e, a partir de um movimento contínuo e gradativo, é possível que os educandos exerçam sua cidadania plena primando pela defesa de seus direitos para que, de fato, gozem a dignidade humana.

Candau et al. (2003) enfatizam o poder de concretização sistemática de uma cultura de direitos humanos que possui a educação em direitos humanos, quando essa é trabalhada cotidianamente. As autoras Horta (2000), Sacavino (2000) e os autores Aquino e Araújo (2001) compartilham da mesma perspectiva. 
Conforme Sime (1991, apud CANDAU et al., 2003), a educação em direitos humanos precisa basear-se na vida cotidiana, pautando-se em três princípios: pedagogia da indignação, pedagogia da admiração e pedagogia das convicções. A pedagogia da indignação trata-se de uma pedagogia que, sob o olhar de rebeldia aos acontecimentos de violações de direitos, escandaliza toda forma de violência e opressão ao invés de consentir. A pedagogia da admiração é aquela que permite a partilha da alegria de viver e de verificar mudanças individuais e coletivas. A pedagogia das convicções trata-se de tomar como eixo central a vida cotidiana e promover convicções como: a vida, a justiça, a esperança, a liberdade, a criticidade, dentre outros valores.

Para a autora Benevides (2000 apud DIAS; PORTO, 2010, p. 32):

\begin{abstract}
A educação em Direitos Humanos é essencialmente a formação de uma cultura de respeito à dignidade humana através da promoção e da vivência dos valores de liberdade, da justiça, da igualdade, da solidariedade, da cooperação, da tolerância e da paz. Portanto, a formação desta cultura significa criar, influenciar, compartilhar e consolidar mentalidades, costumes, atitudes, hábitos e comportamentos que decorrem, todos, daqueles valores essenciais citados - os quais devem se transformar em práticas.
\end{abstract}

Conforme argumenta a autora, essa educação possui três aspectos norteadores do processo educativo: o primeiro diz respeito à natureza permanente, continuada e global da educação em direitos humanos; o segundo volta-se para a mudança e o terceiro aspecto referese aos valores, visto que uma educação que se preocupa apenas com a transmissão de conhecimentos não promove transformações.

Ainda que seja incontestável a relevância de se educar para o respeito à diversidade, a Educação em Direitos Humanos não se restringe a esse conceito, pois ela precisa ser redirecionada para o "objetivo concreto de redução e eliminação de todas as formas de discriminação e violência” (DIAS; PORTO, 2010, p. 33). Assim, a dignidade, liberdade, igualdade, cidadania e historicidade norteiam as reflexões e organização metodológica acerca das relações humanas.

Para Teixeira (2005), a educação em direitos humanos é entendida como uma educação para a democracia e trata-se de um processo que deve ser vivenciado de maneira que, em momento algum, o educando se esqueça de que é um cidadão. Deve contemplar a formação intelectual e a informação, a educação moral e a educação do comportamento, formando uma tríade que envolve tanto o conhecimento, quanto os aspectos político e axiológico. 
A autora Schilling (2005), também admite a educação em direitos humanos como essencial para a construção de uma cidadania democrática. Carvalho, J. S. (2004), além de dispor da mesma concepção, acrescenta que a educação deve ser fundada no respeito aos princípios fundamentais da dignidade humana.

Crítica ao modelo econômico neoliberal, a autora Sacavino (2000) propõe à educação em direitos humanos os seguintes elementos: educação para o "nunca mais"; desenvolvimento de metodologias voltadas à formação de sujeitos de direitos e atores sociais; promoção do "empoderamento" ". Trilha na mesma direção a autora Candau (2005), acrescentando aos elementos anteriores a visão integral dos direitos.

Carbonari (2011), em consonância com o Plano Nacional de Educação em Direitos Humanos (PNEDH), entende a educação em direitos humanos como um processo multidimensional e sistemático. A característica "sistemático", para o autor, refere-se à articulação de momentos, estratégias e dimensões e a multidimensionalidade diz respeito à complexidade do que almeja a educação em direitos humanos e, conforme o PNEDH:

[...] se traduz na perspectiva da "apreensão de conhecimentos historicamente construídos sobre direitos humanos", da "afirmação de valores, atitudes e práticas sociais", da "formação de uma consciência cidadã", do "desenvolvimento de processos metodológicos participativos", do "fortalecimento de práticas individuais e sociais". (CARBONARI, 2011, p. 121)

A autora Silva (2010) ao discorrer sobre a educação em direitos humanos cita o Plano Nacional de Educação em Direitos Humanos (PNEDH) lançado em 2006, enfatizando que a concepção presente em tal documento vai além da mera contextualização e explicação das diversas variáveis inerentes à educação (aspectos culturais, sociais, políticos e econômicos). A educação em direitos humanos presente no PNEDH compreende também a apreensão dos conteúdos que convergem com a pedagogia para o "nunca mais" e com a pedagogia da indignação, ou seja, é preciso que sejam apresentados aos alunos a história, as conquistas e violações dos direitos, os pactos, legislações, acordos e, mais que apresentados, é preciso que

\footnotetext{
${ }^{3} \mathrm{~A}$ educação para o "nunca mais" refere-se à necessidade do resgate histórico que culminou na Declaração Universal dos Direitos Humanos e à necessidade de cultivar a memória ao invés do esquecimento quanto aos acontecimentos marcados por violações de direitos.

${ }^{4} \mathrm{O}$ "empoderamento" diz respeito, segundo Candau e Sacavino (2000), ao ato de possibilitar que os povos (principalmente os que historicamente tiveram menos poder na sociedade) sejam potencializados e passem a ser atores sociais. O "empoderamento" favorece a organização dos grupos sociais minoritários para que mantenham participação ativa na sociedade civil.
} 
tais conteúdos sejam trabalhados e refletidos de maneira abrangente, contínua, interdisciplinar e transversal (CARDOSO, 2009).

Além da apreensão de conteúdos, Silva (2010) também destaca que a educação em direitos humanos sob a ótica do PNEDH deve articular os conteúdos citados acima com valores e comportamentos éticos e deve pautar-se no conceito de cidadania ativa, sem que se perca a ideia de vivência cotidiana e de "colocar em prática".

De acordo com Viola, Barreira e Pires (2011), a educação em direitos humanos é a formação de uma cidadania ativa e crítica, que reconhece os(as) alunos(as) como sujeitos de direitos que constroem sua autonomia. É, ademais, a construção da memória que historicamente é ocultada na tentativa de que não haja reivindicação de direitos por uma sociedade que pode ser (trans)formada criticamente através da educação.

Nessa perspectiva, a educação em direitos humanos luta por uma "educação mais humana" e procura desconstruir preconceitos, culturas discriminatórias e ideologias depreciativas históricas, inclusive no que diz respeito à mulher.

\section{EM BUSCA DE UMA “EDUCAÇÃO MAIS HUMANA: AS RELAÇÕES SOCIAIS DE GÊNERO E A EDUCAÇÃO}

Todos os movimentos sociais, bem como todas as lutas pelo reconhecimento dos direitos daqueles que, historicamente, tiveram menos poder na sociedade e, por conseguinte, pouco participaram dos processos de decisões sobre interesses coletivos, estão intimamente ligados à luta pela concretização de uma cultura dos direitos humanos. Então, a educação em direitos humanos tem como uma das premissas o empoderamento de grupos minoritários.

Uma das lutas travadas ainda hoje se refere à violência contra a mulher. Violência aqui não é entendida apenas como sinônimo de violência doméstica, e sim como um conceito mais amplo que permeia as relações de gênero.

Conforme Araújo (2010, p. 20-21), a violência de gênero "expressa uma forma particular de violência global mediatizada pela ordem patriarcal que delega aos homens o direito de dominar e controlar suas mulheres, podendo para isso usar a violência”.

A ordem patriarcal, nessa perspectiva, é fator importante na produção da violência de gênero, já que embasa as representações de gênero. Nessa ordem patriarcal, foram atribuídas à mulher, historicamente, funções domésticas, como a criação dos filhos, a preparação do 
alimento, o cuidado com o lar, a preservação da família, e ao homem couberam as funções públicas.

Assim como salienta Brabo (2005, p. 31), “[...] todos os sistemas humanos de organização são culturais. São os seres humanos que elaboram normas e costumes que irão condicionar os comportamentos sociais", porém, muitas vezes as funções atribuídas às mulheres são apresentadas como decorrentes da contingência biológica.

Para as próprias mulheres o "ser mulher" era sustentado nos princípios da obediência, respeitabilidade, castidade, comunidade doméstica, particularista e antipolítica (BRABO, 2005).

Com a expansão do modo de produção capitalista, mudanças começaram a ocorrer afetando a configuração das famílias e a posição da mulher na sociedade. A passagem da mulher da esfera privada para a pública a partir da inserção da mulher no mercado de trabalho representou um avanço significativo quanto ao declínio do modelo de família patriarcal. Porém, é esse modelo que ainda dá suporte às relações de gênero, se mantém como tema atual e comporta fatos históricos de opressão contra a mulher.

O conceito de gênero não é similar ao conceito de sexo. Segundo Teles (2007, p. 3839), "gênero se constrói socialmente de acordo com o tempo histórico vivido em cada sociedade, enquanto 'sexo’ teria uma caracterização biológica com destaque para os aspectos físicos do ser feminino ou ser masculino".

A mesma autora aponta que:

\begin{abstract}
Gênero deve ser empregado para explicitar uma ordem social e institucional que impulsiona a construção sociocultural de ser mulher e de ser homem, o que tem determinado desigualdades históricas entre os sexos. A construção institucional se dá em níveis econômico, social, político e cultural. Essa construção direcionada para a proteção do status quo reproduz a discriminação contra as mulheres e poderá ser denominada também "discriminação de gênero". (TELES, 2007, p. 50, grifo da autora).
\end{abstract}

Nesse mesmo sentido, Muraro e Puppin (2001) conceituam gênero como oposição às mentalidades conservadoras que tomam como natural a desvalorização da mulher e, portanto, que tomam o homem como superior. Para as autoras, no século XX surge uma nova categoria de gênero que dá conta do papel das mulheres na história e que acrescenta às discussões a categoria "classe social”, já que essa também faz parte das opressões históricas. 
Gênero é um conceito adotado pelo feminismo, pois tal conceito reforça de maneira sistemática a fragilidade das explicações biológicas para a submissão do sexo feminino. Com o uso de gênero o movimento feminista pôde enfrentar o modelo androcêntrico da ciência e continuar impulsionando lutas em defesa dos direitos e da dignidade das mulheres (TELES, 2007).

O movimento feminista representa importante meio de luta por mudanças efetivas, por transformações sociais e emancipação das mulheres. Manifesta-se por meio de movimentos públicos, nos espaços acadêmicos, políticos, culturais, religiosos e populares, questionando paradigmas históricos que oprimem as mulheres.

Segundo Carvalho, M. E. P. (2009, p. 14), "feminismo é tanto uma ideologia da liberação das mulheres quanto um teoria crítica do sexismo (discriminação de sexo baseada na ideologia da inferioridade da mulher), da visão androcêntrica de mundo e da dominação masculina".

O movimento feminista repercutiu na elaboração de documentos jurídicos internacionais que tratam da equidade de gênero. Dentre tais documentos citamos a Convenção de Belém do Pará, que reconheceu como violação dos direitos humanos a violência contra a mulher. Houve manifestações das mulheres anteriormente às comemorações do $50^{\circ}$ aniversário da Declaração Universal dos Direitos Humanos em prol de novos paradigmas e reforçou-se também neste momento que a violência contra as mulheres constitui violação dos direitos humanos.

Sob o olhar de que a educação em direitos humanos favorece a construção de uma sociedade equitativa, justa, harmônica e sob o olhar de que, para isso, é necessário o empoderamento dos desfavorecidos historicamente através de um trabalho engajado politicamente, considera-se de suma importância que a escola esteja atenta não só ao educar para os direitos humanos, mas também ao educar para desconstruir as relações de gênero que menosprezam a mulher.

Conforme Brabo (2005, p. 92), a educação deve:

[...] proporcionar à menina, por meio de sua socialização, situações que a levem a adquirir algumas características consideradas masculinas, como autonomia, liderança, entre outras, para que elas consigam romper antigos preconceitos e costumes que ainda hoje dificultam a independência, a profissionalização e a autonomia da mulher. 
Para tanto, é de extrema importância que as atividades de intervenção sejam trabalhadas na educação básica de maneira diária, gradativa, contínua e transversal. Conforme Aquino e Araújo (2001, p. 11),

A construção de relações sociais mais justas, solidárias e democráticas, que respeitem as diferenças físicas, psíquicas, ideológicas, culturais e socioeconômicas de seus membros, [...] passa, necessariamente, pela incorporação, nas práticas cotidianas, de princípios e valores já conhecidos, mas nunca de fato consolidados por nenhuma cultura, como os que já foram consagrados em 1948 na Declaração Universal dos Diretos Humanos.

É preciso que a educação, na pretensão de ser "mais humana", favoreça a vivência cotidiana das premissas da educação em direitos humanos, que, por sua vez, é capaz de tornar meninos e, principalmente meninas, sujeitos de sua própria história, sujeitos solidários(as), empáticos(as) e empoderados(as).

\section{CONSIDERAÇÕES FINAIS}

Educar em direitos humanos e para que as relações de gênero sejam equitativas é um processo lento, constante, que deve permanecer por toda a vida dos seres humanos. Além disso, para que mudanças significativas fossem observadas em curto prazo, seria necessário que a grande maioria das relações sociais que as crianças estabelecessem, fossem favoráveis ao processo de educação na perspectiva de gênero e de direitos humanos, ou seja, tanto na escola quanto no meio familiar e público, seria necessário que a criança vivenciasse o respeito, a solidariedade, o sentimento de igualdade nas diferenças, que tivesse contato com princípios democráticos, justos, igualitários, com a conscientização de seus direitos e deveres, com a consciência cidadã.

Embora pareça uma realidade ideal, nem sempre é possível que tais requisitos sejam contemplados, dificultando, assim, a percepção de mudanças rápidas. Muitas vezes os ambientes familiar e público não promovem relações sociais favoráveis à formação das crianças e, portanto, não possibilitam aos cidadãos historiciarem-se, tonarem-se autores conscientes de sua própria história.

Traçadas essas considerações, pode-se dizer que a escola possui responsabilidade ainda maior quanto à formação de homens e mulheres em direitos humanos e gênero. Uma 
vez que a criança não convive em ambiente favorável a essa formação fora da escola, no âmbito escolar ela precisa perceber diferenças quanto aos princípios e relacionamentos entre os seres humanos que ali trabalham, que ali estudam e precisa ter assegurada uma formação pautada nos princípios da Declaração Universal dos Direitos Humanos, do Plano Nacional de Educação em Direitos Humanos (PNEDH) e de tantos outros documentos que abordam as premissas da temática gênero e direitos humanos.

Quanto à formação dos(as) professores(as) em direitos humanos e gênero, Candau et al. (2003, p.70) afirma que os educadores e educadoras:

[...] devem ser concebidos como profissionais e cidadãos e cidadãs, agentes socioculturais e políticos [...], mobilizadores de processos pessoais e grupais de natureza cultural e social, construtores de conhecimentos, valores e práticas.

Para que emerja uma nova sociedade, livre de uma democracia de baixa intensidade ${ }^{5}$, com cidadãos ativos, conscientes de seus direitos e do processo histórico que permitiu a consolidação desses direitos, com seres humanos que gozem plenamente das condições de dignidade humana e capazes de reconhecer a dignidade humana do outro, é preciso que todos tenham acesso a uma educação em/para os direitos humanos desde os primeiros anos de vida.

Sendo assim, é preciso que os(as) educadores(as) interiorizem a importância da educação em direitos humanos refletindo cotidianamente em sua prática pedagógica ações voltadas à mudança do quadro de violações, violência e marginalização posto até então.

Sobre a importância do(a) professor(a) na efetivação de uma educação em direitos humanos e, consequentemente, efetivação de um processo sistemático que visa a grandes transformações em toda a sociedade, Padilha (2005, p. 169) questiona:

[...] Como alguém que não se respeita, que não respeita os seus próprios direitos, que às vezes nem os conhece e que não sabe defendê-los, poderia ensinar outro alguém sobre o exercício de algum direito ou sobre qualquer outro conteúdo de forma crítica e emancipadora? Ou como alguém que está desacostumado a ser ético e agir, socialmente com justiça? Ou, ainda, como um professor que se deixa vencer pela rotina, por mais dura que possa ser, pode contribuir para a formação de sujeitos que exerçam plenamente a sua cidadania e saibam defender os seus direitos civis, sociais e políticos?

${ }^{5} \mathrm{O}$ termo "democracia de baixa intensidade" foi utilizado por Sacavino (2000) para designar o sistema democrático implantado a partir da ideologia neoliberal. Trata-se de uma democracia que limita-se a focalizar meramente a igualdade perante a lei e o direito ao voto. 
EDUCAÇÃO EM DIREITOS HUMANOS E RELAÇÕES SOCIAIS DE GÊNERO: DISCUSSÕES EM BUSCA DE UMA "EDUCAÇÃO MAIS HUMANA"

Como assinala Dallari (2004, p.19), “os professores têm uma possibilidade muito grande de influenciar a vida social [...]” e, quando eles se mantêm em posição neutra diante dos acontecimentos, poupando seus alunos e alunas de compreender a realidade e criar o desejo de mudança, consentem com o que está ocorrendo, mesmo que não concordem.

Se, porém, levam reflexões sobre o assunto para as atividades pedagógicas que desenvolvem, colocando-se em posição ativa, podem motivar e auxiliar em processos de mudança e participação (NASCIMENTO, 2000). Ainda segundo Dallari (2004), “os professores dispõem da possibilidade de influir para correção de vícios históricos e distorções profundamente injustas".

Desse modo, para que a almejada "educação mais humana" seja de fato um dos fatores determinantes na afirmação de cultura dos direitos humanos que permeie relações sociais, transforme-as e realmente favoreça processos de democratização, é essencial que os(as) educadores(as) assumam práticas pedagógicas que vão ao encontro dos objetivos da educação em direitos humanos, libertando-se de seus próprios tabus e preconceitos. Além disso, é preciso que a educação em direitos humanos tenha caráter axiológico, político, ocorra no cotidiano e esteja presente nos pequenos detalhes. Aliás, pequenos detalhes muitas vezes são repletos de significados e podem tornar-se instrumentos de realizações grandiosas em prol de toda a humanidade.

\title{
EDUCATION IN HUMAN RIGHTS AND SOCIAL AFFAIRS GENDER: DISCUSSIONS ON A SEARCH "EDUCATION MORE HUMAN"
}

\begin{abstract}
This text aims to reflect through bibliographic study on the conditions of human rights education, especially that relates to social gender relations, and show theoretical and methodological aspects that can support the pedagogical practice in the classroom. We understand that, among the neoliberal context and the negative consequences that such an ideology caused the human rights education becomes one of the fundamental instruments for the realization of a culture of human rights that is capable of transforming social relations and practices, including relationships social gender, contributing to the perpetuation of a
\end{abstract}


"education more human". Therefore, it is essential that the education has to make a political nature, walk in a perspective of axiological training and happen daily.

Keywords: Education; Human Rights; Genre; Neoliberalism; Teacher

\section{EDUCACIÓN EN DERECHOS HUMANOS Y ASUNTOS SOCIALES DE GÉNERO: DEBATES EN UNA BÚSQUEDA "EDUCACIÓN MÁS HUMANA"}

\section{Resumen}

Este texto pretende reflejar a través del estudio bibliográfico sobre las condiciones de la educación en derechos humanos, especialmente en relación con las relaciones sociales de género, y presentar los aspectos teóricos y metodológicos que pueden apoyar la práctica pedagógica en el aula. Entendemos que, en medio de un contexto neoliberal y las consecuencias negativas que tal ideología causaron que la educación en derechos humanos se convierte en uno de los instrumentos fundamentales para la realización de una cultura de derechos humanos de que es capaz de transformar las relaciones y prácticas sociales, incluyendo las relaciones género social, contribuyendo a la perpetuación de una "educación humana". Por lo tanto, es esencial que la educación tiene que tomar una naturaleza política, caminar en la perspectiva de la formación axiológica y sucederá al día.

Palabras clave: Educación; Derechos Humanos; Género; El Neoliberalismo; Profesor

\section{REFERÊNCIAS}

AQUINO, J. G.; ARAÚJO, U. F. Os Direitos Humanos na Sala de Aula: A ética como tema transversal. São Paulo: Moderna, 2001.

ARAÚJO, Maria de Fátima. Mulheres e Relações de Gênero: Trabalho e Violência. In:

BRABO, T. S. A. M. (Org.). Gênero, Educação, Trabalho e Mídia. São Paulo: Ícone, 2010. p. 19-28

BENEVIDES, Maria Vitória. Educação para a cidadania e em direitos humanos. In: Encontro Nacional de didática e prática de ensino, 9 . Anais. Olhando a qualidade do ensino a partir da sala de aula. Águas de Lindóia: FEUSP, v.2, p.165-177, 1998. 
BEHRING, E. R.; BOSCHETTI, I. Política Social: fundamentos e história. 9. ed. São Paulo: Cortez, 2011.

. Educação em direitos humanos: de que se trata? Palestra de abertura do Seminário de Educação em Direitos Humanos, São Paulo, 18 fev. 2000. Disponível em: <htpp:www.hottopos.com/conenit6/victoria.htm> Acesso em: 18 de Nov. 2014.

BRABO, Tânia Suely Antonelli Marcelino. Cidadania da mulher professora. São Paulo: Ícone, 2005.

. (Org.). Gênero, Educação e Política: Múltiplos Olhares. São Paulo: Ícone, 2009. BRASIL. Ministério da Justiça. Programa nacional de direitos humanos II. Brasília: Secretaria de Estado dos Direitos Humanos, 2002. Disponível em:

<http://www.nevusp.org/downloads/down007.pdf>. Acesso em: 18 de Nov. 2014.

Plano nacional de educação em direitos humanos. Brasília: Secretaria Especial dos Direitos Humanos, Ministério da Educação, 2003.

CANDAU, V. M. Educação em direitos humanos: principais desafios. Rio de Janeiro: 2005 (mimeo).

. Educação em direitos humanos no Brasil: realidade e perspectivas. In: CANDAU, V. M.; SACAVINO, S. (Orgs.). Educar em direitos humanos: construir democracia. Rio de Janeiro: DP\&A, 2000. p. 72-99.

; SACAVINO, S. (Orgs.). Educar em direitos humanos: construir democracia. Rio de Janeiro: DP\&A, 2000.

et. al. Oficinas Pedagógicas de Direitos Humanos. 6. ed. Petrópolis, RJ: Vozes, 2003.

CARBONARI, Paulo César. Educação em direitos humanos: esboço de reflexão conceitual. In: BITTAR, E. C. B. Direitos Humanos no Século XXI. (Org.). Rio de Janeiro: Forense Universitária; São Paulo: ANPHED; Brasília: Secretaria Especial dos Direitos Humanos, 2009.

Educação em direitos humanos: por uma nova pedagogia. In: VIOLA, S. E. A.; ALBUQUERQUE, M. Z. (Orgs.). Fundamentos para educação em direitos humanos. São Leopoldo: Sinodal, 2011. p. 119-127.

CARDOSO, Clodoaldo Meneguello. Educação infantil em direitos humanos. Observatório de Direitos Humanos, Dez. 2009. Disponível em <http://unesp.br/portal\#!/observatorio_ses/biblioteca/artigos-edh/>. Acesso em: 18 de Nov. 2014.

CARVALHO, José Sérgio (Org.). Educação, cidadania e direitos humanos. Petrópolis: Vozes, 2004. 
CARVALHO, Maria Eulina Pessoa de. Feminismo e construção da cidadania das mulheres: avanços e desafios nos campos da educação, trabalho e política no início do século XXI. In: BRABO, T. S. A. M. (Org.). Gênero, Educação e Política: Múltiplos Olhares. São Paulo: Ícone, 2009. p. 11-34

DALLARI. Dalmo A. Um breve histórico dos direitos humanos. In: CARVALHO, J. S. (Org.). Educação, cidadania e direitos humanos. Petrópolis: Vozes, 2004. p. 19-42.

DIAS, A. A.; PORTO, R. C. C. A Pedagogia e a Educação em Direitos Humanos: subsídios para a inserção da temática da Educação em Direitos Humanos nos cursos de Pedagogia. In: FERREIRA, L. F. G.; ZENAIDE, M. N. T.; DIAS, A. A. (Org). Direitos Humanos na Educação Superior: Subsídios para a Educação em Direitos Humanos na Pedagogia. João Pessoa: Editora Universitária da UFPB, 2010, p.29-63.

HORTA, M. D. M. R. Educar em direitos humanos: compromisso com a vida. In: CANDAU, V. M.; SACAVINO, S. (Orgs.). Educar em direitos humanos: construir democracia. Rio de Janeiro: DP\&A, 2000. p. 125-139.

MARRACH, Sonia Alem. Neoliberalismo e educação. 2015. Disponível em: <http://www.cefetsp.br/edu/eso/neoeducacao1.html >. Acesso em: 21 de Jan. 2016.

MURARO, R. M.; PUPPIN, A. B. MULHER, Gênero e Sociedade. Rio de Janeiro: Redelume Dumará: FAPERJ, 2001.

NASCIMENTO, M. G. C. A. A dimensão política da formação de professores/as. In: CANDAU, V. M.; SACAVINO, S. (Org). Educar em direitos Humanos: construir democracia. Rio de Janeiro: DP\&A, 2000, p.115-124.

PADILHA, Paulo R. Educação em direitos humanos sob a ótica dos ensinamentos de Paulo Freire. In: SCHILLING. F. (Org.). Direitos Humanos e educação. São Paulo: Cortez, 2005, p. 166-176.

PEREIRA, William Eufrásio Nunes. Do Estado Liberal ao Neoliberalismo. Interface. 2004. Disponível em: < http://www.spell.org.br/documentos/download/21331>. Acesso em: 15 de Jan. 2016.

SACAVINO, Suzana. Educação em direitos humanos e democracia. In: CANDAU, V. M.; SACAVINO, S. (Orgs.). Educar em direitos humanos: construir democracia. Rio de Janeiro: DP\&A, 2000. p. 36-48.

SCHILLING, Flávia. (Org.). Direitos Humanos e Educação. São Paulo: Cortez, 2005.

SILVA, A. M. M. Direitos Humanos na Educação Básica: qual o significado?. In: SILVA, A. M. M.; TAVARES, C. (Orgs.). Políticas e fundamentos da educação em direitos humanos. São Paulo: Cortez, 2010. p. 41-63.

SIME, L. Derechos Humanos y Educación. In: Comision Episcopal de Accion Social (CEAS) et. alii. Educar em Derechos Humanos: Reflexones a Partir de la Experiencia. Lima: Grafinace, 1991. 
EDUCAÇÃO EM DIREITOS HUMANOS E RELAÇÕES SOCIAIS DE GÊNERO: DISCUSSÕES EM BUSCA DE

TEIXEIRA, Beatriz de Basto. Escolas para os direitos humanos e a democracia. In:

SCHILlING, F. (Org.). Direitos Humanos e Educação. São Paulo: Cortez, 2005. p. 145-167.

TELES, Maria Amélia de Almeida. O que são os direitos humanos das mulheres. São Paulo: Brasiliense, 2007.

VIOLA, S. E. A.; BARREIRA, C.; PIRES, T. V. Direitos humanos: de movimento social à proposta educativa. In: VIOLA, S. E. A.; ALBUQUERQUE, M. Z. (Orgs.). Fundamentos para educação em direitos humanos. São Leopoldo: Sinodal, 2011. p. 143-156.

Data de recebimento: $27 / 01 / 2016$

Data de aceite: 08/03/2016 